PLEASE NOTE:

This is the author's version of the manuscript accepted for publication in Intonational Grammar in Ibero-Romance: Approaches across linguistic subfields. Changes resulting from the publishing process, namely editing, corrections, final formatting for printed or online publication, and other modifications resulting from quality control procedures, may have been subsequently added.

The published version can be found in: Filipe, M. G., Frota, S., Villagomez, A., \& Vicente, S. G. (2016). Prosody in portuguese children with high-functioning autism. In M. Armstrong, N. C. Henriksen, \& M. M. Vanrell (Eds.), Intonational Grammar in Ibero-Romance: Approaches across linguistic subfields (pp. 277-294). Philadelphia, USA: John Benjamins. doi:10.1075/ihll.6.13fil 


\title{
Prosody in Portuguese Children with High-Functioning Autism
}

\author{
Marisa G. Filipe ${ }^{1}$, Sónia Frota ${ }^{2}$, Adrienne Villagomez ${ }^{3}$, and Selene G. Vicente ${ }^{1}$ \\ ${ }^{1}$ Universidade do Porto \\ ${ }^{2}$ Universidade de Lisboa \\ ${ }^{3}$ University of North Carolina at Chapel Hill
}

\begin{abstract}
Author Note
Marisa G. Filipe, Faculdade de Psicologia e Ciências da Educação da Universidade do Porto; Sónia Frota, Centro de Linguística, Faculdade de Letras da Universidade de Lisboa; Adrienne Villagomez, University of North Carolina at Chapel Hill; and Selene G. Vicente, Faculdade de Psicologia e Ciências da Educação da Universidade do Porto.

Correspondence concerning this article should be addressed to Marisa Filipe, Laboratório de Fala, Faculdade de Psicologia e Ciências da Educação da Universidade do Porto, Rua Alfredo Allen, 4200-135 Porto, Portugal. E-mail: labfala@fpce.up.pt.
\end{abstract}


Abstract: There is a lack of research investigating prosody in Portuguese children with autism. In this chapter, we analyze 15 Portuguese children aged 5-9 years with highfunctioning autism (HFA) in comparison to their typically developing peers. We also evaluated nonverbal intelligence, vocabulary, phonological awareness, pragmatics, attention, and executive functions. Statistical analyses, using pairwise matching of nonverbal intelligence and chronological age, suggested that children with HFA have difficulties perceiving and imitating prosodic patterns, as well as difficulties understanding or effectively producing some of the communicative functions conveyed by prosody. Findings suggested a significant positive correlation between prosody and other language domains. Additionally, two case studies were conducted to further discuss the prosodic impairments.

Keywords: Prosody, prosodic impairments, autism, high-functioning autism, Portuguese

\section{Introduction ${ }^{1}$}

Prosodic systems (e.g., prosodic structure, intonation, and rhythm) play a key role in spoken language. These systems mediate the phonetic substance of speech within a wide range of linguistic and communicative functions (Ladd, 2008; Peppé, 1998). Atypical prosodic patterns generally act as significant barriers to communication and may also affect the process of language acquisition (Baltaxe \& Simmons, 1985; Johnson \& Jusczyk, 2001; Thiessen \& Saffran, 2003). Considering these findings, we aimed to analyze prosodic impairments in Portuguese children with high-functioning autism.

\footnotetext{
${ }^{1}$ This research was supported by the Portuguese Foundation for Science and Technology (PEstC/PSI/IU0050/2011, SFRH/BD/64166/2009, and PEst-OE/LIN/UI0214/2013).
} 
Although there may be several methods of assessing prosodic skills, for the purposes of our study we focused on the dimensions of prosodic form and function. Prosodic form corresponds to the acoustic and auditory-perceptual characteristics of the signal, such as the type of melodic pattern heard in speech. Prosodic function represents the pragmatic and linguistic meanings of prosody in communication. As prosodic patterns can facilitate perceptual judgments by providing added meaning through syntactic, semantic, and pragmatic information, functional analysis is extremely important to understand and interpret expressive language. Two illustrative examples include sentence-type distinctions, such as the difference between declarative and question intonation, and the expression of focus, which highlights important words. The distinction between formal and functional levels is relevant because children with prosodic impairments can have different types of problems: (1) they can mimic and discriminate prosodic patterns with no effort (formal level), but exhibit problems understanding meaning and producing adequate prosody for social or interactional purposes (functional level); (2) they cannot mimic and discriminate prosodic patterns (formal level), but are able to understand the meanings and produce adequate prosody for social or interactional purposes (functional level); or (3) they cannot mimic and discriminate prosodic patterns (formal level), and have problems with understanding the meanings and producing adequate prosody for social or interactional purposes (functional level).

Although speakers constantly use prosody, when comparing the volume of research conducted on prosody and other language domains, it is clear that the current state of knowledge about prosodic impairments lingers behind. Fortunately, during the last few years, atypical prosody has attracted researchers' attention. An important focus of study has been the relationship between prosody and language abilities. Researchers have investigated the role of prosody in the acquisition of language in typically developing children and have 
shown its relevance for speech segmentation and the learning of several linguistic categories and structures (Christophe, Millotte, Bernal, \& Lidz, 2008; Johnson \& Jusczyk, 2001; Thiessen \& Saffran, 2003). Overall, prosodic abilities appear to play a pivotal role in language acquisition, at least in typically developing children (Höhle, 2009; Morgan \& Demuth, 1996). Prosody is essential to language development during the early years, and some aspects of it continue to develop throughout the individual's life (Wells, Peppé, \& Goulandris, 2004). However, few studies go beyond the first few years of life, and little is known about the relationship between language skills and prosodic skills in later childhood.

Prosodic abilities have also attracted researchers’ attention in a large number of clinical populations with language and communicative impairments, such as autistic spectrum disorder (e.g., McCann \& Peppé, 2003; McCann, Peppé, Gibbon, O’Hare, \& Rutherford, 2007; Shriberg et al., 2001). Autism spectrum disorder (ASD) is a neurodevelopmental disorder characterized by social communication impairment and restricted interests or repetitive behaviors (American Psychiatric Association, 2013). ASD is characterized by a wide range of variability, from low-functioning autism to high-functioning autism (HFA). Individuals who are more severely affected typically present more profound impairments and lower intellectual functioning. In comparison, individuals with HFA are characterized by higher verbal and intellectual functioning. As a consequence, individuals with ASD vary greatly in their language abilities and range from nonverbal to being fluent (Kjelgaard \& Tager-Flusberg, 2001; Tager-Flusberg, Paul, \& Lord, 2005). As language and communication acquisition is a major challenge faced by children with ASD, considerable advances have been made since 1980 in delineating and understanding the communication and language problems of these children (e.g., Jarrold, Boucher, \& Russell, 1997; Kurita, 1985; Lord, \& Paul, 1997; Loveland, Landry, Hughes, Hall, \& McEvoy, 1988; Tager-Flusberg, 1981, 1993, 1996). 
In fact, deficits in the pragmatic use of language are a defining feature of HFA, and communication impairments in ASD are often marked by atypicalities in prosody (e.g., Baltaxe, 1984; Bonneh, Levanon, Dean-Pardo, Lossos, \& Adini, 2011; Diehl, Watson, Bennetto, McDonough, \& Gunlogson, 2009; Green \& Tobin, 2009; Kjelgaard \& TagerFlusberg, 2001; McCann \& Peppé, 2003; Nadig \& Shaw, 2012; Paul, Augustyn, Klin, \& Volkmark, 2005; Paul, Orlovski, Marcinko, \& Volkmar, 2009; Sharda et al., 2010; Shriberg et al., 2001; Tager-Flusberg et al., 2005). Deficits in prosody have been identified as characteristic of ASD since Kanner's original description of autism (1943; Paul et al., 2009; Tager-Flusberg et al., 2005; Young, Diehl, Morris, Hyman, \& Bennetto, 2005). Children, adolescents, and adults with HFA present impairments in pragmatic and prosodic aspects of language despite having other well-developed aspects of language, including phonological, morphosyntactic, or lexical-semantic abilities (e.g., Shriberg et al., 2001; Stone \& CaroMartinez, 1990; Tager-Flusberg, 2003).

Atypicality in expressive prosody in individuals with ASD is well documented in the literature. They are often reported to have unusual prosody and speak in a monotone voice, with an exaggerated intonation, or with singsong prosody (Baltaxe \& Simmons, 1985; BaronCohen \& Staunton, 1994; Fay \& Schuler, 1980; Frith, 1991; McCann \& Peppé, 2003; Schreibman, Kohlenberg, \& Britten, 1986; Van Lancker, Cornelius, \& Kreimanet, 1989). The most commonly reported atypicalities in prosodic abilities are related to rhythm, speech rate, or intonation patterns (e.g., McCann \& Peppé, 2003; Paul et al., 2005; Shriberg et al., 2001).

The studies analyzing both productive and comprehensive prosodic abilities demonstrated that children with ASD perform lower than typically developing individuals on prosodic tasks (matched for chronological age, verbal, and/or nonverbal measures; e.g., Järvinen-Pasley, Peppé, King-Smith, \& Heaton, 2008; Peppé et al., 2007). For instance, McCann et al. (2007) reported that 31 participants with HFA (matched for verbal mental age, 
sex, and socioeconomic status) showed impairments in some area of prosodic functioning, according to assessment with the Profiling Elements of Prosodic Systems-Communication test (PEPS-C; Peppé \& McCann, 2003). In particular, difficulties with the discrimination and production of prosodic differences were found as well as problems with the judgment and production of questions, statements, emotional preferences, prosodic breaks, and focus. These pragmatic and prosodic impairments in language are so pervasive that they often distinguish children with ASD from other developmental language delays (Rice, Warren, \& Betz, 2005; Wilkinson, 1998). Recently, it has been suggested that prosody is indicative of specific cognitive and social functioning (Diehl \& Berkovits, 2010).

An important and understudied question concerns whether prosody is independent from aspects such as nonverbal intelligence, executive function, attention, or other neuropsychological domains. For instance, Jones et al. (2011) found that the intelligence quotient had a strong and significant effect on the recognition of emotional prosody. Nevertheless, it is not clear from earlier research whether impaired prosody is related to language impairments and/or to specific neurodevelopmental profiles.

Although there is research quantifying expressive and receptive disorders in ASD, there is a lack of research on this topic for European Portuguese-speaking children, and prior to the current study, little research has attempted to link impaired prosody to neurodevelopmental profiles in ASD. In this paper, we explored prosodic impairments in Portuguese children with HFA between the ages of 5 and 9 years old. The first goal was to examine disorders linked to acoustic and auditory-perceptual characteristics of the signal (i.e., the formal level), and/or difficulties related to conveying and comprehending important meanings expressed using prosody (i.e., the functional level). Our second aim was to analyze the association between prosody and other developmental domains including nonverbal intelligence, vocabulary, phonological awareness, pragmatics, attention, and executive function. Furthermore, given 
the importance of variability within the autism spectrum, two case studies were conducted to illustrate prosodic impairments in children with HFA.

\section{Method}

\subsection{Participants}

Fifteen Portuguese children with HFA, from the districts of Porto and Aveiro (in northern Portugal), participated in this study. The children were aged 5 to 9 years $(M=7.33, S D=$ 1.39) and all were male. A team of professional child psychiatrists and psychologists made the diagnosis of ASD based on assessment and parent interviews. Specifically, the Autism Diagnostic Observation Schedule (ADOS; Lord et al., 1989) and the Autism Diagnostic Interview-Revised (ADI-R; Lord, Rutter, \& Le Couteur, 1994) were used. All participants met the DSM-5 (American Psychiatric Association, 2013) criteria for autism. Exclusion criteria in the study included diagnoses of schizophrenia, obsessive-compulsive disorders, attention deficit hyperactivity disorder, and learning disabilities. The 15 children with HFA were matched with 15 typically developing children for age $(M=7.27, S D=1.43)$ and nonverbal intelligence in order to eliminate nonspecific factors, such as intellectual disability, as performance explanations. All participants were native speakers of European Portuguese, had no visual or hearing impairments, and demonstrated a level of nonverbal intelligence at or above the expected average for their age, as assessed with the Raven Coloured Progressive Matrices test (RCPM; Raven, 1995; Simões, 2000). The groups were not significantly different on measures of nonverbal intelligence (RCPM) and attention (Children's Color Trails Test, CCTT; Llorente, Williams, Satz, \& D`Elia, 2003), but they were significantly different on measures of language (Griffiths Mental Development Scales 2-8 years - Subscale Language, GMDS; Luiz et al., 2007), receptive vocabulary (Peabody Picture 
Vocabulary Test, PPVT; Dunn \& Dunn, 2007; Vicente, Sousa, \& Silva, 2011), phonological awareness (Assessment of reading skills in European Portuguese - Metalinguistic Awareness of the Phoneme Test (ALEPE; Sucena \& Castro, 2012), pragmatics (Pragmatic Protocol; Prutting \& Kirschner, 1987), and executive functioning (Behavior Rating Inventory of Executive Function, BRIEF; Gioia, Isquith, Guy, \& Kenworthy, 2000; Teles \& Vicente, 2011) (see Table 1).

Table 1 about here

\subsection{Material}

The European Portuguese Version of Profiling Elements of Prosody in SpeechCommunication (PEPS-C; Filipe \& Vicente, 2011; Peppé \& McCann, 2003) was implemented to evaluate receptive and expressive prosodic skills. All children were assessed using the 12 PEPS-C tasks at two levels: formal and functional. The formal level assesses the auditory discrimination and voice skills required to perform the tasks, whereas the functional level evaluates prosodic abilities in four communicative categories. While the following is a brief summary of the formal and functional tasks, more detailed information about the original version can be found at http://www.peps-c.com/.

1. PEPS-C formal level tasks:

1.1 Short-Item Discrimination: ability to discriminate short prosodic items. Participants choose if two low-pass filtered one-word utterances are the same or different.

1.2 Short-Item Imitation: ability to imitate short prosodic items. Participants imitate one-word utterances.

1.3 Long-Item Discrimination: ability to discriminate long prosodic items. Participants choose if two low-pass filtered sentences are the same or different. 
1.4 Long-Item Imitation: ability to imitate long prosodic items. Participants imitate multiword utterances.

2. PEPS-C functional level tasks:

2.1 Turn-End Reception: ability to understand question or declarative intonation. Participants see a picture and hear a statement or a question (e.g., carrot vs. carrot?). Afterwards, they choose whether they heard a question or a statement.

2.2 Turn-End Expression: ability to produce question or declarative intonation. If the participants see a picture of a person reading about food, they will say the name of the food item with the prosody that expresses a statement (e.g., carrot.); if the participants see a picture of someone offering food, they will say the name of the food item using question intonation (e.g., carrot?).

2.3 Affect Reception: ability to understand liking or disliking intonation. Participants see a picture (e.g., cheese) and hear like or dislike intonation. Afterwards, they choose if they heard like or dislike intonation regarding the item presented.

2.4 Affect Expression: ability to produce liking or disliking intonation. Participants see a picture of food, and they say the name of the food item with the prosody that expresses like (e.g., cheese) or dislike (e.g., cheese), according to their preferences. Afterwards, they indicate whether they like or do not like the food item.

2.5 Chunking Reception: ability to comprehend syntactically ambiguous phrases disambiguated by prosody. For instance, participants see a picture and hear a phrase that represents either two or three pictures of objects (e.g., fish fingers, and fruit vs. fish, fingers, and fruit). Afterwards, the participants choose if they heard a phrase that represents two or three pictures/objects.

2.6 Chunking Expression: ability to produce syntactically ambiguous phrases disambiguated by prosody. For instance, participants see two or three pictures (e.g., fish 
fingers and fruit vs. fish, fingers, and fruit) and describe what they have seen.

2.7 Focus Reception: ability to identify focus. Participants see a picture with two colors and hear a phrase with focus on one of the colors (e.g., blue and BLACK socks). After, the participant identifies which color was focused in the statement (e.g., black).

2.8 Focus Expression: ability to produce focus. Participants see a picture (e.g., a red cow with a ball) and hear a sentence that does not match the picture (e.g., The black cow has the ball). Afterwards, the participant is asked to correct the speaker (e.g., No, the RED cow has the ball).

Participants were also evaluated in several domains with the following measures: (1) Nonverbal Intelligence: Raven’s Coloured Progressive Matrices (RCPM; Raven, 1995; Simões, 2000); (2) Receptive Vocabulary: Peabody Picture Vocabulary Test (PPVT; Dunn \& Dunn, 2007; Vicente et al., 2011); (3) Phonological Awareness: Assessment of reading skills in European Portuguese - Metalinguistic Awareness of the Phoneme Test (ALEPE; Sucena \& Castro, 2012); (4) Pragmatics: Pragmatic Protocol (Prutting \& Kirschner, 1987); (5) Attention: Children's Color Trails Test (CCTT; Llorente, Williams et al., 2003); and (6) Executive Functions: Behavior Rating Inventory of Executive Function (BRIEF; Gioia et al., 2000; Teles \& Vicente, 2011).

\subsection{Procedure}

Written parental informed assent was obtained. Children were seen individually in a suitable location (a quiet room with adequate lighting conditions). The assessment was carried out in accordance with the manual instructions and performed across three to five sessions completed within a month and lasting approximately 45 minutes each. The order of the tests alternated between verbal and nonverbal tasks and was the same for all participants, as follows: 1) RCPM; 2) PEPS-C; 3) CCTT; 4) ALEPE; 5) PPVT; and 6) Pragmatic Protocol. 
The BRIEF questionnaire was administered to parents during one of the sessions. For PEPSC, half of the participants started with the receptive tasks and the other half with the expressive tasks. Their expressive performance was recorded and subsequently re-evaluated.

\section{Results}

\subsection{Performance on the PEPS-C tasks}

First, we controlled for the order of administering the receptive and expressive tasks of PEPS-C. This variable did not have an effect on the main results (Short-Item Discrimination: $F(1,28)=2.076, p>.05$; Short-Item Imitation: $F<1$; Long-Item Discrimination: $F(1,28)=$ 1.164, $p>$.05; Long-Item Imitation: $F(1,28)=2.633, p>.05$; Turn-End Reception: $F<1$; Turn-End Expression: $F<1$; Affect Reception: $F<1$; Affect Expression: $F<1$; Chunking Reception: $F<1$; Chunking Expression: $F<1$; Focus Reception: $F<1$; Focus Expression: $F$ $(1,28)=1.657, p>.05)$

On the PEPS-C test, children could achieve a maximum score of 16 on each task. The receptive tasks were scored as correct or incorrect by the researcher, and the expressive tasks were scored independently by three raters. Inter-rater agreement was established, and the Cohen’s kappa coefficient calculated was highly significant $(K=0.856 ; p<.001)$, suggesting a high level of agreement between the raters for the expressive tasks.

The results were analyzed to investigate the differences between autistic and typically developing children in terms of their prosody. In general, children with ASD demonstrated lower performance on prosodic abilities. The differences were statistically significant for Short-Item Discrimination $\left(F(1,28)=4.244, p=.049 ; \eta^{2}=.132\right)$, Short-Item Imitation $(F$ 
$\left.(1,28)=10.975, p=.003 ; \eta^{2}=.282\right)$, Long-Item Imitation $\left(F(1,28)=6.316, p=.018 ; \eta^{2}=\right.$ $.184)$, Turn-End Reception $\left(F(1,28)=4.847, p=.036 ; \eta^{2}=.148\right)$, Turn-End Expression $(F$ $\left.(1,28)=4.959, p=.034 ; \eta^{2}=.150\right)$, and Affect Expression $\left(F(1,28)=6.322, p=.018 ; \eta^{2}=\right.$ .184; see Figure 1).

Figure 1 about here

Furthermore, in order to analyze the relationship of possible prosodic impairments to other basic deficits, Pearson correlations were calculated between variables. We used a composite score for the prosody tasks (overall mean scores). Prosodic abilities in general were strongly correlated with vocabulary (Pearson’s $r=.69 ; p<.0001$ ), phonological awareness (Pearson's $r=.73 ; p<.0001$ ), and pragmatics (Pearson’s $r=.78 ; p<.0001$ ), and they were moderately correlated with nonverbal intelligence (Pearson’s $\mathrm{r}=.52 ; p=.003$ ). There was no correlation between prosodic skills and the other abilities tested: executive functions (Pearson’s $r=.16 ; p>.05$ ) and attention (Pearson's $r=.19 ; p>.05$ ). We also calculated the correlations between all the PEPS-C tasks and the other measures (see Table 2). Overall, nonverbal intelligence, vocabulary, phonological awareness, and pragmatics were correlated with most of the prosodic tasks, whereas executive function was correlated only with Short-Item Imitation. There was no correlation between attention and other PEPS-C tasks.

Given the importance of individual differences and the wide variability that characterizes the autism spectrum, it is crucial to explore the dynamic relationships between prosody and other neurodevelopmental skills that might be moderating these interactions. Case study analysis appeared to be a valuable approach to further investigate this 
relationship. Two case studies of children with HFA were conducted to further examine and illustrate prosodic deficits.

\subsection{Case A}

Case A was diagnosed with HFA at age 3 and was 7 years old when he participated in this study. He attended a regular school in an inclusive setting. Figure 2 illustrates his performance on each of the domains assessed and compares it with the performance of a typically developing peer of the same chronological age and nonverbal intelligence. This comparison consisted of the standardized scores for each test, which were derived from raw scores using the norming information gathered when the test was developed. The standardized scores represent the number of standard deviations the performance is above or below the mean. A standardized score of 0 means is the same as the mean, and this score can be positive or negative, indicating whether it is above or below the mean, respectively. By comparing Case A's performance with that of the typically developing child, we identified difficulties in each of the areas assessed (i.e., prosodic abilities, vocabulary, phonological awareness, pragmatics, attention, and executive functions).

Figure 2 about here

Case A demonstrated difficulties with prosody (see Figure 3). Specifically, A seemed to experience increased difficulty in tasks that involve longer stimuli and that are more demanding on working memory (i.e., Long-Item Discrimination, Long-Item Imitation, Chunking Reception, Chunking Expression, Focus Reception, and Focus Expression). Moreover, he exhibited difficulties in the Short-Item Imitation task. In this case, it is possible 
that executive function deficits are influencing A's prosodic performance. This could have an important impact in the context of implementing interventions.

Figure 3 about here

\subsection{Case B}

Case B was also diagnosed with HFA at age 3, and he was five years old at the time of the study. He attended a regular kindergarten. By comparing B's performance with that of a child of similar nonverbal mental age and chronological age (see Figure 4), we found that Case B exhibits a very significant deficit in prosodic ability congruent with other impairments. In fact, difficulties were also found in each of the assessed areas.

Figure 4 about here

B's performance on PEPS-C showed a generalized prosodic deficit, exhibiting problems in all tasks (Short-Item Discrimination, Short-Item Imitation, Long-Item Discrimination, Long-Item Imitation, Turn-End Reception, Turn-End Expression, Affect Reception, Affect Expression, Chunking Reception, Chunking Expression, Focus Reception, and Focus Expression; see Figure 5). B’s prosodic profile was very poor and consistent, the performance on the Affect expression task being the most affected. As demonstrated in this case, prosodic performance is altered at both form and functional levels.

Figure 5 about here 


\section{Discussion}

As prosody is a crucial communication skill used to convey meaning, in the present study we explored prosodic impairments in children on the autistic spectrum in relation to other neurodevelopmental domains. Fifteen children with HFA, between 5 and 9 years of age, were evaluated for prosodic abilities, nonverbal intelligence, vocabulary, phonological awareness, pragmatics, attention, and executive function. The participants with HFA were matched with 15 typically developing peers on nonverbal intelligence and chronological age, and two case studies were conducted. The group analysis showed significant differences in the prosodic performance of children with HFA compared to typically developing peers, and suggested that language abilities were strongly correlated with prosody. The results are consistent with the findings of studies on other languages, in which children with HFA performed significantly poorer than controls on at least one prosodic task (e.g., Peppé el al., 2007; Rutherford, Baron-Cohen, \& Wheelwright, 2002).

In this study, Portuguese children with HFA present impairments in the detection and production of auditory-perceptual differences in short items (at the formal level), as well as problems with questions and statements and with emotional expression (at the functional level). No problems emerged in the understanding or production of focus and chunking, although this was found in a sample of English-speaking children with HFA (Peppé et al., 2007; Shriberg et al., 2001). This difference could be explained by the control of other neuropsychological skills in the present study (e.g., attention skills) or specific language characteristics (as European Portuguese includes properties of both Romance and Germanic languages in its phonology and prosody, namely prominence-related, rhythmic, and 
intonational properties, posing challenging questions for the study of prosodic impairments; Frota, 2000, 2014; Frota \& Vigário, 2001).

Also, this study demonstrates a clear relationship between prosody and other language abilities (such as phonological awareness, receptive vocabulary, and pragmatics). It could be argued that the participants performed significantly lower than their typically developing peers because they did not understand the tasks; however, the tasks included two examples and two training items, which ensured that participants understood each task. Additionally, the instructions are suitable for children over 4 years old with linguistic or developmental disorders.

From a conceptual standpoint, it is tempting to conclude that prosodic impairment is simply a manifestation of the language impairments of children with ASD because it is known that receptive prosody has primary importance in language acquisition (Morgan \& Demuth, 1996). Moreover, further in development, previous studies have shown that prosody still correlates strongly with language (e.g., McCann et al., 2007). It is also possible that an early failure to utilize prosodic bootstrapping may have contributed to the children's later language impairments. Furthermore, a receptive prosodic impairment may have implications not only for understanding the many functions of prosody, but also for general language comprehension. To address these questions, future studies should evaluate children with other clinical conditions (e.g., specific language impairments) and conduct longitudinal studies.

From our results, it also appears that prosodic impairments shown by children with HFA are not associated with other neurodevelopmental domains, but with a unique characteristic of social communication in ASD. However, as illustrated by Case A, future studies should consider the possible implications of other neuropsychological processes in the assessment of prosodic impairments. For instance, the Theory of Executive Dysfunction identifies difficulties in planning, initiation, and inhibition skills as a core deficit that 
underlines this disorder (Rajendran \& Mitchell, 2007). In this theoretical view, people with ASD misunderstand prosody because they find difficulties with these abilities (e.g., to inhibit the default response). More studies are needed to understand if disordered prosody is more likely to be due to other impairments, such as executive dysfunction, or a simple result of delayed language.

Moreover, although many aspects of communication improve over time in individuals with HFA, prosodic difficulties often remain stable (Shriberg et al., 2001; Paul et al., 2005; Diehl et al., 2009). Despite their enduring nature, prosodic impairments are often not targeted in therapy (McCann et al., 2007; Paul et al., 2005). The developmental path of language in children with HFA is a challenge that requires further research.

The field of language and communication promises to continue as a basic area of research and intervention into the challenging problems of ASD. The present paper contributes to this area of research and intervention with respect to prosodic impairments in children with HFA. Understanding the differences that distinguish children with HFA from typically developing children makes it possible to target certain skills areas through intervention. Furthermore, the current findings have implications for the clinical management of prosodic deficits in clinical populations. It is crucial to ensure that speakers do not rely on prosody to send messages when a child with ASD has a receptive prosodic impairment. Similarly, listeners should be aware that they cannot rely on prosody to understand meaning when a child has impaired expressive prosody.

It is notable that the study of prosody together with other language skills in ASD has not been further explored in the context of linguistics, cognitive science, and psychology approaches to HFA. The present study aimed to examine this link. Future research should further explore these questions with larger sample sizes and more robust statistic analyses in 
order to verify if the present pattern of findings can be replicated within and across languages.

\section{References}

American Psychiatric Association. (2013). Diagnostic and statistical manual of mental disorders (5th ed.). Arlington, VA: American Psychiatric Publishing. doi: 10.1176/appi.books.9780890425596.744053

Baltaxe, C. (1984). Use of contrastive stress in normal, aphasic and autistic children. Journal of Speech and Hearing Research, 27, 97-105.

Baltaxe, C., \& Simmons, J. Q. (1985). Prosodic development in normal and autistic children. In E. Schopler \& G. B. Mesibov (Eds.), Communication problems in autism (pp. 95125). New York, NY: Plenum Press. doi: 10.1007/978-1-4757-4806-2_7

Baron-Cohen, S., \& Staunton, R. (1994). Do children with autism acquire the phonology of their peers? An examination of group identification through the window of bilingualism. First Language, 14, 241-248. doi: 10.1177/014272379401404216

Bonneh, Y. S., Levanon, Y., Dean-Pardo, O., Lossos, L., \& Adini, Y. (2011). Abnormal speech spectrum and increased pitch variability in young autistic children. Frontiers in Human Neuroscience, 4, 237. doi: 10.3389/fnhum.2010.00237

Christophe, A., Millotte, S., Bernal, S., \& Lidz, J. (2008). Bootstrapping lexical and syntactic acquisition. Language and Speech, 51(1-2), 61-75. doi:

\section{$10.1177 / 00238309080510010501$}

Diehl, J. J., \& Berkovits, L. (2010). Is prosody a diagnostic and cognitive bellwether of autism spectrum disorders? In A. Harrison (Ed.), Speech disorders: Causes, treatments, and social effects (pp. 159-176). New York, NY: Nova Science Publishers, Inc. 
Diehl, J. J., Watson, D., Bennetto, L., McDonough J., \& Gunlogson, C. (2009). An acoustic analysis of prosody in high-functioning autism. Applied Psycholinguistics, 30(3), 385404. doi:10.1017/S0142716409090201

Dunn, D. M., \& Dunn, L. M. (2007). Peabody Picture Vocabulary Test (4th ed., manual). Minneapolis, MN: NCS Pearson, Inc.

Fay, W., \& Schuler, A. L. (1980). Emerging language in autistic children. Baltimore, MD: University Park Press.

Filipe, M. G., \& Vicente S. G. (2011). Teste de competências prosódicas para falantes do Português Europeu [A test of prosodic abilities for European Portuguese speakers]. In A. S. Ferreira, A. Verhaeghe, D. R. Silva, L. S. Almeida, R. Lima, \& S. Fraga (Eds.), Proceedings of the VIII Iberoamerican Congress of Psychological Assessment (pp. 447-463). Lisbon, Portugal: Sociedade Portuguesa de Psicologia. Retrieved from http://sigarra.up.pt/fpceup/publs_pesquisa.formview?p_id=75969

Frith, U. (1991). Autism and Asperger syndrome. Cambridge, England: Cambridge University Press.

Frota, S. (2000). Prosody and focus in European Portuguese: Phonological phrasing and intonation. New York, NY: Garland Publishing.

Frota, S. (2014). The intonational phonology of European Portuguese. In S-A. Jun (Ed.), Prosodic typology II (pp. 6-42). Oxford, England: Oxford University Press. doi: 10.1093/acprof:oso/9780199567300.003.0002

Frota, S., \& Vigário, M. (2001). On the correlates of rhythmic distinctions: The European/Brazilian Portuguese case. Probus, 13(2), 247-273.

Gioia, G. A., Isquith, P. K., Guy, S. C., \& Kenworthy, L. (2000). Behavior Rating Inventory of Executive Function. Odessa, FL: Psychological Assessment Resources, Inc. 
Green, H., \& Tobin, Y. (2009). Prosodic analysis is difficult ... but worth it: A study in high functioning autism. International Journal of Speech-Language Pathology, 11(4), 308315. doi: $10.1080 / 17549500903003060$

Höhle, B. (2009). Bootstrapping mechanisms in first language acquisition. Linguistics, 47(2), 359-382. doi: 10.1515/LING.2009.013

Jarrold, C., Boucher, J., \& Russell, J. (1997). Language profiles in children with autism: Theoretical and methodological implications. Autism, 1, 57-76.

Järvinen-Pasley, A., Peppé, S., King-Smith, G., \& Heaton, P. (2008). The relationship between form and function level receptive prosodic abilities in autism. Journal of Autism and Development Disorders, 38(7), 1328-1340. doi: 10.1007/s10803-007-0520$\mathrm{Z}$

Johnson, E. K., \& Jusczyk, P. W. (2001). Word segmentation by 8-month-olds: When speech cues count more than statistics. Journal of Memory and Language, 44(4), 548-567. doi: 10.1006/jmla.2000.2755

Jones, C. R. G., Pickles, A., Falcaro, M., Marsden, A. J. S., Happé, F., Scott, S. K., ... Charman, T. (2011). A multimodal approach to emotion recognition ability in autism spectrum disorders. Journal of Child Psychology and Psychiatry, 52(3), 275-285. doi: 10.1111/j.1469-7610.2010.02328.x

Kanner, L. (1943). Autistic disturbances of affective contact. Nervous Child, 2, 217-250.

Kjelgaard, M. A., \& Tager-Flusberg, H. (2001). An investigation of language profiles in autism: Implications for genetic subgroups. Language and Cognitive Processes, 15, 122. doi: $10.1080 / 01690960042000058$

Kurita, H. (1985). Infantile autism with speech loss before the age of 30 months. Journal of the American Academy of Child Psychiatry, 24(2), 191-196.

Ladd, D. R. (2008). Intonational phonology (2nd ed., Vol. 119). Cambridge, England: Cambridge University Press. 
Llorente, A. M., Williams, J., Satz, P., \& D`Elia, L. F. (2003). Children’s Color Trails Test: Professional manual. Lutz, FL: Psychological Assessment Resources.

Lord, C., \& Paul, R. (1997). Language and communication in autism. In D. J. Cohen \& F. R. Volkmar (Eds.), Handbook of autism and pervasive development disorders (2nd ed., pp. 195-225). New York, NY: John Wiley.

Lord, C., Rutter, M. L., Goode, S., Heemsbergen, J., Jordan, H., Mawhood, L., \& Schopler, E. (1989). Autism Diagnostic Observation Schedule: A standardized observation of communicative and social behavior. Journal of Autism and Developmental Disorders, 19(2), 185-212. doi: 10.1007/BF02211841

Lord, C., Rutter, M. L., \& Le Couteur, A. (1994). The Autism Diagnostic InterviewRevised: A revised version of a diagnostic interview for caregivers of individuals with possible pervasive developmental disorders. Journal of Autism and Developmental Disorders, 24(5), 659-685. doi: 10.1007/BF02172145

Loveland, K., Landry, S., Hughes, S., Hall, S., \& McEvoy, R. (1988). Speech acts and the pragmatic deficits of autism. Journal of Speech and Hearing Research, 31, 593-604.

Luiz, D. M, Barnard, A., Knoesen, M. P., Kotras, N., Horrocks S., McAlinden, P., Challis, D., \& O’Connell, R. (2007). Escala de Desenvolvimento Mental de Griffiths — Extensão Revista (Revisão de 2006) dos 2 aos 8 anos: Manual de Administração [Griffiths Mental Development Scales-Extended Revised (Revision 2006) from 2 to 8 years: Administration Guide]. Lisbon, Portugal: Cegoc-Tea.

McCann, J., \& Peppé, S. (2003). Prosody in autism spectrum disorders: A critical review. International Journal of Language \& Communication Disorders, 38(4), 325-350. doi: $10.1080 / 1368282031000154204$

McCann, J., Peppé, S., Gibbon, F., O’Hare, A., \& Rutherford, M. (2007). Prosody and its relationship to language in school-aged children with high-functioning autism. 
International Journal of Language and Communication Disorders, 42(6), 682-702. doi: $10.1080 / 13682820601170102$

Morgan, J. L., \& Demuth, K. (1996). Signal to syntax: An overview. In J. L. Morgan \& K. Demuth (Eds.), Signal to syntax: Bootstrapping from speech to grammar in early acquisition (pp. 1-22). New York, NY: Lawrence Erlbaum Associates.

Nadig, A., \& Shaw H. (2012). Acoustic and perceptual measurement of expressive prosody in high-functioning autism: Increased pitch range and what it means to listeners. Journal of Autism and Development Disorders, 42(4), 499-511. doi: 10.1007/s10803011-1264-3

Paul, R., Augustyn, A., Klin, A., \& Volkmark, F. R. (2005). Perception and production of prosody by speakers with autism spectrum disorders. Journal of Autism and Development Disorders, 35(2), 205-220. doi: 10.1007/s10803-004-1999-1

Paul, R., Orlovski, S. M., Marcinko, H. C., \& Volkmar, F. R. (2009). Conversational behaviors in youth with high-functioning ASD and Asperger syndrome. Journal of Autism and Developmental Disorders, 39(1), 115-125. doi: 10.1007/s10803-008-06071

Peppé, S. (1998). Investigating linguistic prosodic ability in adult speakers of English (Unpublished doctoral dissertation). University College London, London.

Peppé, S., \& McCann, J. (2003). Assessing intonation and prosody in children with atypical language development: The PEPS-C test and the revised version. Clinical Linguistics \& Phonetics, 17(4/5), 345-354. doi: 10.1080/0269920031000079994

Peppé, S., McCann, J., Gibbon, J., O’Hare, A., \& Rutherford, M. (2007). Receptive and expressive prosodic ability in children with high-functioning autism. Journal of Speech, Language, and Hearing Research, 50, 1015-1028. doi: 10.1044/1092-4388(2007/071) 
Prutting C., \& Kirchner, D. (1987) A clinical appraisal of the pragmatic aspects of language. Journal of Speech and Hearing Disorders, 52, 105-119.

Rajendran, G., \& Mitchell, P. (2007). Cognitive theories of autism. Developmental Review, 27, 224-260. doi: 10.1016/j.dr.2007.02.001

Raven, J. C. (1995). Manual for the Coloured Progressive Matrices (Revised). Windsor, UK: NFRE-Nelson.

Rice, M. L., Warren, S. F., \& Betz, S. K. (2005). Language symptoms of developmental language disorders: An overview of autism, Down syndrome, fragile X, specific language impairment, and Williams syndrome. Applied Psycholinguistics, 26, 7-27. doi: 10.1017.S0142716405050034

Rutherford, M. D., Baron-Cohen, S., \& Wheelwright, S. (2002). Reading the mind in the voice: A study with normal adults and adults with Asperger syndrome and high functioning autism. Journal of Autism Developmental Disorders, 32(3), 189-194. doi: 10.1023/A:1015497629971

Schreibman, L., Kohlenberg, B. S., \& Britten, K. R. (1986). Differential responding to content and intonation components of a complex auditory stimulus by nonverbal and echolalic autistic children. Analysis and Intervention in Developmental Disabilities, 6, 109-125. doi: 10.1016/0270-4684(86)90009-1

Sharda, M., Subhadra, T. P., Sahay, S., Nagaraja, C., Singh, L., Mishra, R., ... Nandini C. S. (2010). Sounds of melody—pitch patterns of speech in autism. Neuroscience Letters, 478(1), 42-45. doi: 10.1016/j.neulet.2010.04.066.

Shriberg, L. D., Paul, R., McSweeny, J. L., Klin, A., Cohen, D. J., \& Volkmar, F. R. (2001). Speech and prosody characteristics of adolescents and adults with high-functioning autism and Asperger syndrome. Journal of Speech, Language, and Hearing Research, 44, 1097-1115. doi: 10.1044/1092-4388(2001/087) 
Simões, M. (2000). Investigações no âmbito da Aferição Nacional do Teste das Matrizes Progressivas Coloridas de Raven (M.P.C.R). Lisbon, Portugal: Fundação Calouste Gulbenkian \& Fundação para a Ciência e Tecnologia.

Stone, W. L., \& Caro-Martinez, L. M. (1990). Naturalistic observations of spontaneous communication in autistic children. Journal of Autism and Developmental Disorders, 20, 437-453. doi: 10.1007/BF02216051

Sucena, A., \& Castro, S. L. (2012). ALEPE - Avaliação da Leitura em Português Europeu [ALEPE. Assessment of Reading Skills in European Portuguese]. Lisbon, Portugal: CEGOC-TEA.

Tager-Flusberg, H. (1981). Sentence comprehension in autistic children. Applied Psycholinguistics, 2, 5-24. doi: 10.1017/S014271640000062X

Tager-Flusberg, H. (1993). What language reveals about the understanding of minds in children with autism. In S. Baron-Cohen, H. Tager-Flusberg, \& D. J. Cohen (Eds.), Understanding other minds: Perspectives from autism (pp. 138-157). Oxford, England: Oxford University Press.

Tager-Flusberg, H. (1996). Current theory and research on language and communication in autism. Journal of Autism and Developmental Disorders, 26, 169-172. doi: 10.1007/BF02172006

Tager-Flusberg, H. (2003). Language impairment in children with complex neurodevelopmental disorders: The case of autism. In Y. Levy \& J. Schaeffer (Eds.), Language competence across populations (pp. 297-321). Mahwah, NJ: Lawrence Erlbaum Associates.

Tager-Flusberg, H., Paul, R., \& Lord, C. (2005). Communication in autism. In F. Volkmar, A. Klin, R. Paul, \& D. Cohen (Eds.), Handbook of autism and pervasive developmental disorders (3rd ed., pp. 335- 364). N.Y.: Wiley \& Sons. 
Teles, S., \& Vicente, S. G. (2011). Behavior Rating Inventory of Executive Function (BRIEF): European Portuguese - Short Parental Version [working research version constructed based on the BRIEF of Gioia, Isquith, Guy, \& Kenworthy, 2000]. Unpublished Material, Centre of Psychology, Faculty of Psychology and Educational Sciences, University of Porto, Porto, Portugal.

Thiessen, E. D., \& Saffran, J. R. (2003). When cues collide: Use of statistical and stress cues to word boundaries by 7- and 9-month-old infants. Developmental Psychology, 39, 706716. doi: 10.1037/0012-1649.39.4.706

Van Lancker, D., Cornelius, C., \& Kreiman, J. (1989). Recognition of emotional-prosodic meanings in speech by autistic, schizophrenic, and normal children. Developmental Neuropsychology, 5, 207-226. doi: 10.1080/87565648909540433

Vicente, S. G., Sousa, A. S., \& Silva, M. A. (2011). European Portuguese Material for Receptive Vocabulary Assessment [working research version constructed based on the PPVT-4 (Form B) of Dunn, \& Dunn, 2007]. Unpublished Material, Centre of Psychology, Faculty of Psychology and Educational Sciences, University of Porto, Porto, Portugal.

Wells, B., Peppé, S., \& Goulandris, A. (2004). Intonation development from five to thirteen. Journal of Child Language, 31, 749-778. doi: 10.1017/S030500090400652X

Wilkinson, K. M. (1998). Profiles of language and communication in autism. Mental Retardation and Developmental Disabilities Research Reviews, 4, 73-79.

Young, E. C., Diehl, J. J., Morris, D., Hyman, S. L., \& Bennetto, L. (2005). The use of two language tests to distinguish pragmatic language problems in children with autism spectrum disorders. Language, Speech, and Hearing Services in Schools, 36, 62-72. doi: 10.1044/0161-1461(2005/006). 
Table 1. Mean $(M)$, standard deviation $(S D)$, and range for age, nonverbal intelligence, attention, language (Griffiths subscale), phonological awareness, vocabulary, pragmatics, and executive functions in the high-functioning autism (HFA) and typically developing (TD) children.

\begin{tabular}{|c|c|c|c|c|c|c|c|}
\hline & \multicolumn{3}{|c|}{ HFA $(n=15)$} & \multicolumn{3}{|c|}{$\mathrm{TD}(n=15)$} & \multirow[t]{2}{*}{$p$ value } \\
\hline & $M$ & $S D$ & Range & $M$ & $S D$ & Range & \\
\hline Age & 7.33 & 1.39 & $5-9$ & 7.27 & 1.43 & $5-9$ & $>.05$ \\
\hline $\begin{array}{l}\text { Nonverbal } \\
\text { Intelligence }\end{array}$ & 24.67 & 3.43 & $17-32$ & 24.40 & 4.54 & $17-32$ & $>.05$ \\
\hline Language & 84.38 & 19.95 & 40-115 & 105.81 & 10.77 & 90-123 & $<.05$ \\
\hline $\begin{array}{l}\text { Phonological } \\
\text { Awareness }\end{array}$ & 7.53 & 5.66 & $0-12$ & 11.20 & 3.09 & $0-12$ & $<.05$ \\
\hline Vocabulary & 113.87 & 36.01 & 53-182 & 141.27 & 32.49 & 99-188 & $<.05$ \\
\hline Pragmatics & 14.27 & 9.86 & $0-27$ & 30 & 30 & .000 & $<.05$ \\
\hline $\begin{array}{l}\text { Executive } \\
\text { Functions }\end{array}$ & 64.93 & 11.09 & 49-88 & 53.87 & 9.60 & $37-71$ & $<.05$ \\
\hline Attention & 1.09 & 0.94 & $0.1-3.0$ & 0.81 & 0.70 & $0.1-2.2$ & $>.05$ \\
\hline
\end{tabular}

Note. $* p \leq .05$ (one-way ANOVA). Maximum score for nonverbal Intelligence $=36$. Score for language: $M=100 ; S D=15$. Maximum score for phonological awareness $=12$. Maximum score for vocabulary $=228$. Maximum score for pragmatics $=30$. Maximum score for executive function problems $=105$. Score for attention problems (Interference index): $M=0.86 ; S D=0.52$. 
Table 2. Correlations between PEPS-C tasks, nonverbal intelligence, phonological awareness, vocabulary, pragmatics, attention, and executive function.

\begin{tabular}{|c|c|c|c|c|c|c|}
\hline PEPS-C Tasks & $\begin{array}{c}\text { Nonverbal } \\
\text { Intelligence }\end{array}$ & $\begin{array}{c}\text { Phonological } \\
\text { Awareness }\end{array}$ & Vocabulary & Pragmatics & Attention & $\begin{array}{l}\text { Executive } \\
\text { Function } \\
\end{array}$ \\
\hline Short-Item Discrimination & $.39 *$ & $.46^{*}$ & $.56 * *$ & $.60 * *$ & -.06 & -.21 \\
\hline Short-Item Imitation & .13 & .16 & .13 & $.64 * *$ & -.25 & $-.37 *$ \\
\hline Long-Item Discrimination & $.46^{*}$ & .25 & $.38^{*}$ & $.63^{* *}$ & -.15 & -.13 \\
\hline Long-Item Imitation & .60 & .34 & .28 & $.72 * *$ & -.07 & -.07 \\
\hline Turn-End Reception & $.45^{*}$ & $.56 * *$ & $.59 * *$ & $.75^{* *}$ & -.14 & -.25 \\
\hline Turn-End Expression & .18 & $.47^{*}$ & $.48^{*}$ & $.52 *$ & -.22 & -.10 \\
\hline Affect Reception & $.69 * *$ & $.81 * *$ & $.70 * *$ & $.64^{* *}$ & -.32 & -.02 \\
\hline Affect Expression & $.40 *$ & $.57 * *$ & $.47 *$ & $.65 * *$ & -.13 & -.06 \\
\hline Chunking Reception & $.39 *$ & $.46^{*}$ & $.56 * *$ & $.47 *$ & -.06 & -.31 \\
\hline Chunking Expression & .13 & .16 & .13 & .33 & -.25 & -.34 \\
\hline Focus Reception & $.46^{*}$ & .25 & $.38 *$ & .10 & -.15 & -.07 \\
\hline Focus Expression & .06 & .43 & .28 & .28 & -.07 & -.17 \\
\hline
\end{tabular}

Note. $* p<.05 . * * p \leq .001$. 
Figure Captions

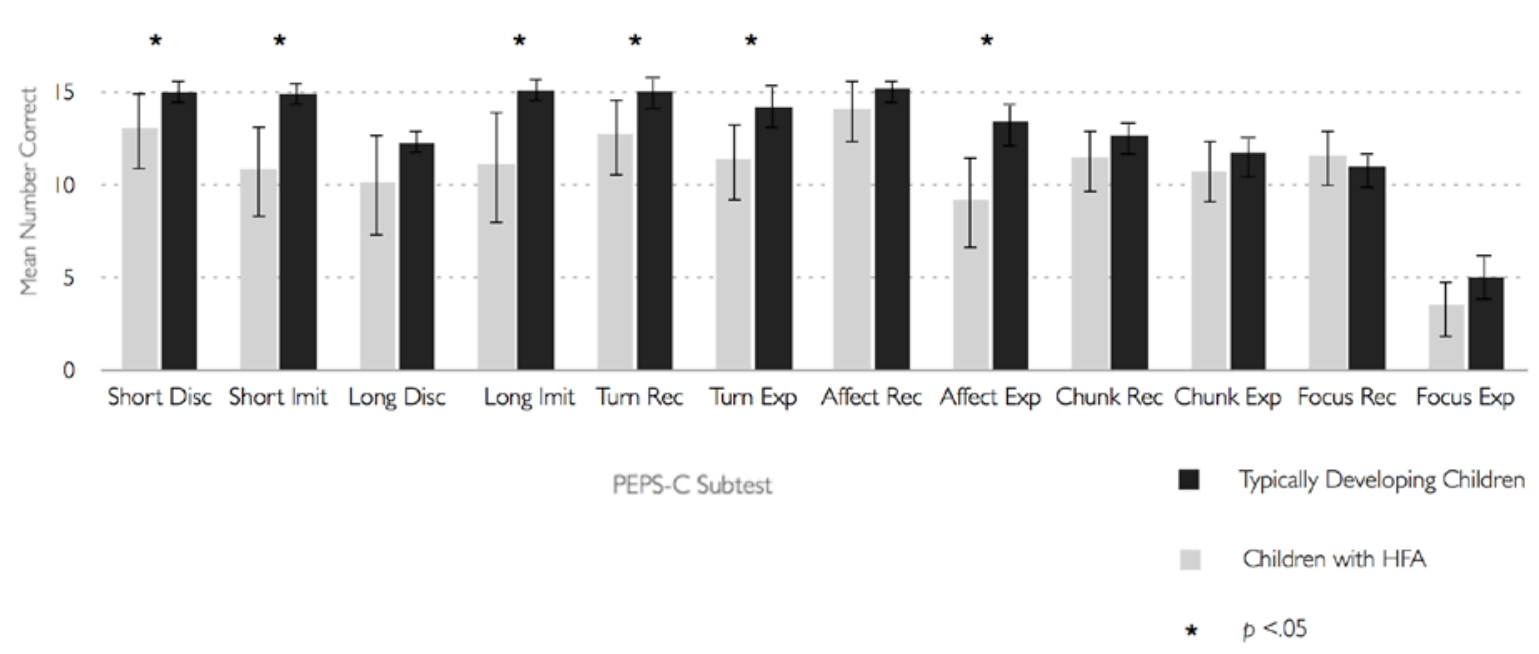

Figure 1. Means scores for the PEPS-C tasks in typically developing children and in children with high-functioning autism (HFA) with the same chronological age and nonverbal intelligence. 


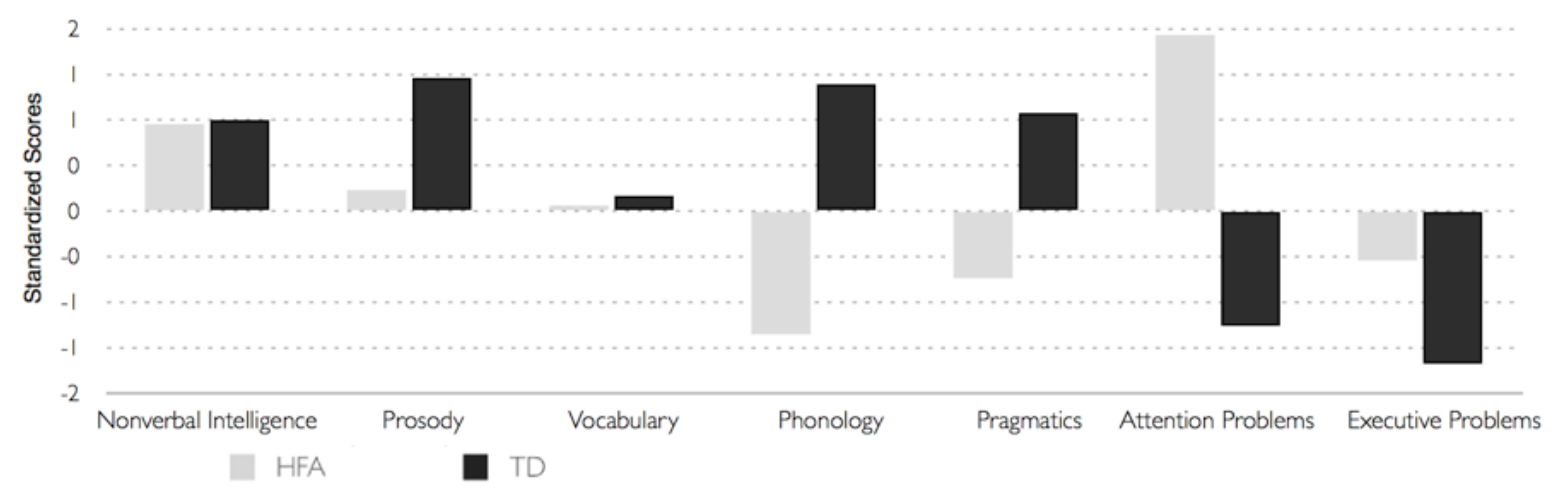

Figure 2. Standardized scores for all the domains assessed for Case A (a child with highfunctioning autism, HFA) and a typically developing peer (TD, a child with the same chronological age and nonverbal intelligence). 


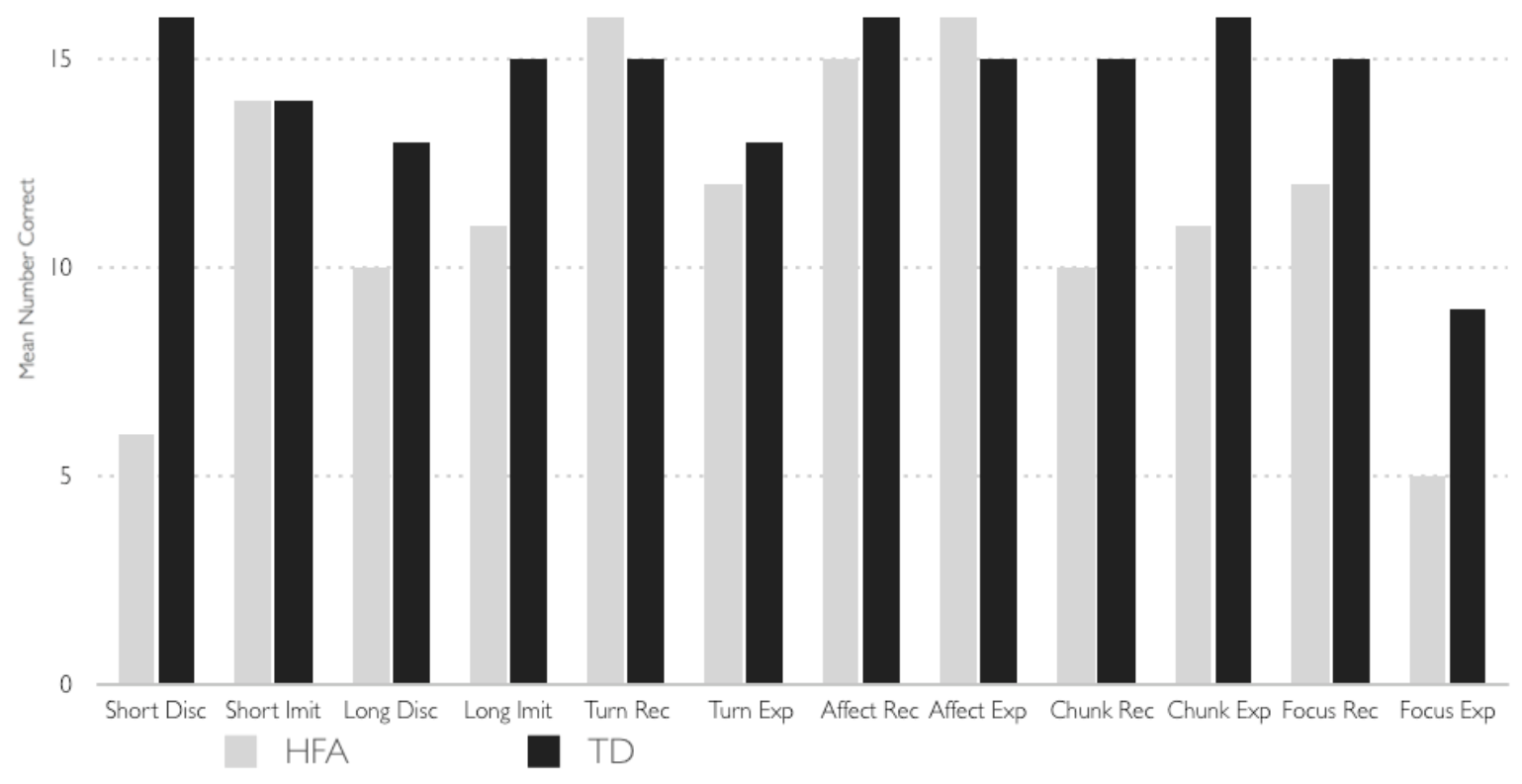

Figure 3. Standardized scores for all the PEPS-C tasks for Case A (a child with highfunctioning autism, HFA) and a typically developing peer (TD, a child with the same chronological age and nonverbal intelligence). 


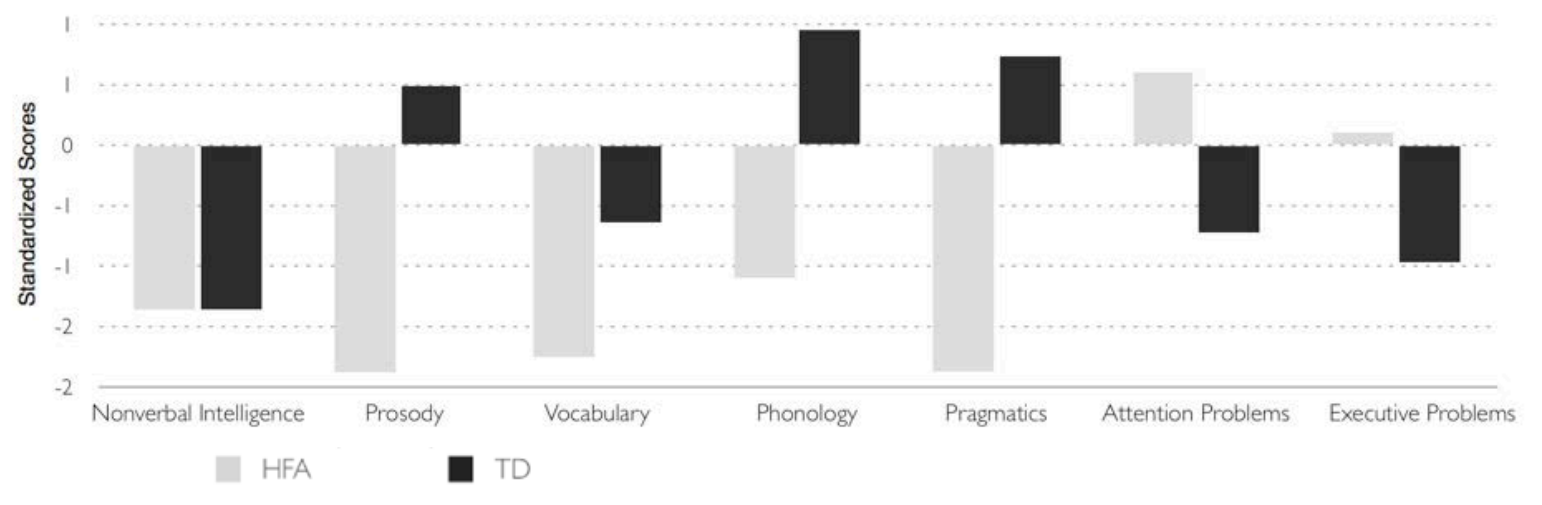

Figure 4. Standardized scores for all the domains assessed for Case B (a child with highfunctioning autism, HFA) and a typically developing peer (TD, a child with the same chronological age and nonverbal intelligence). 


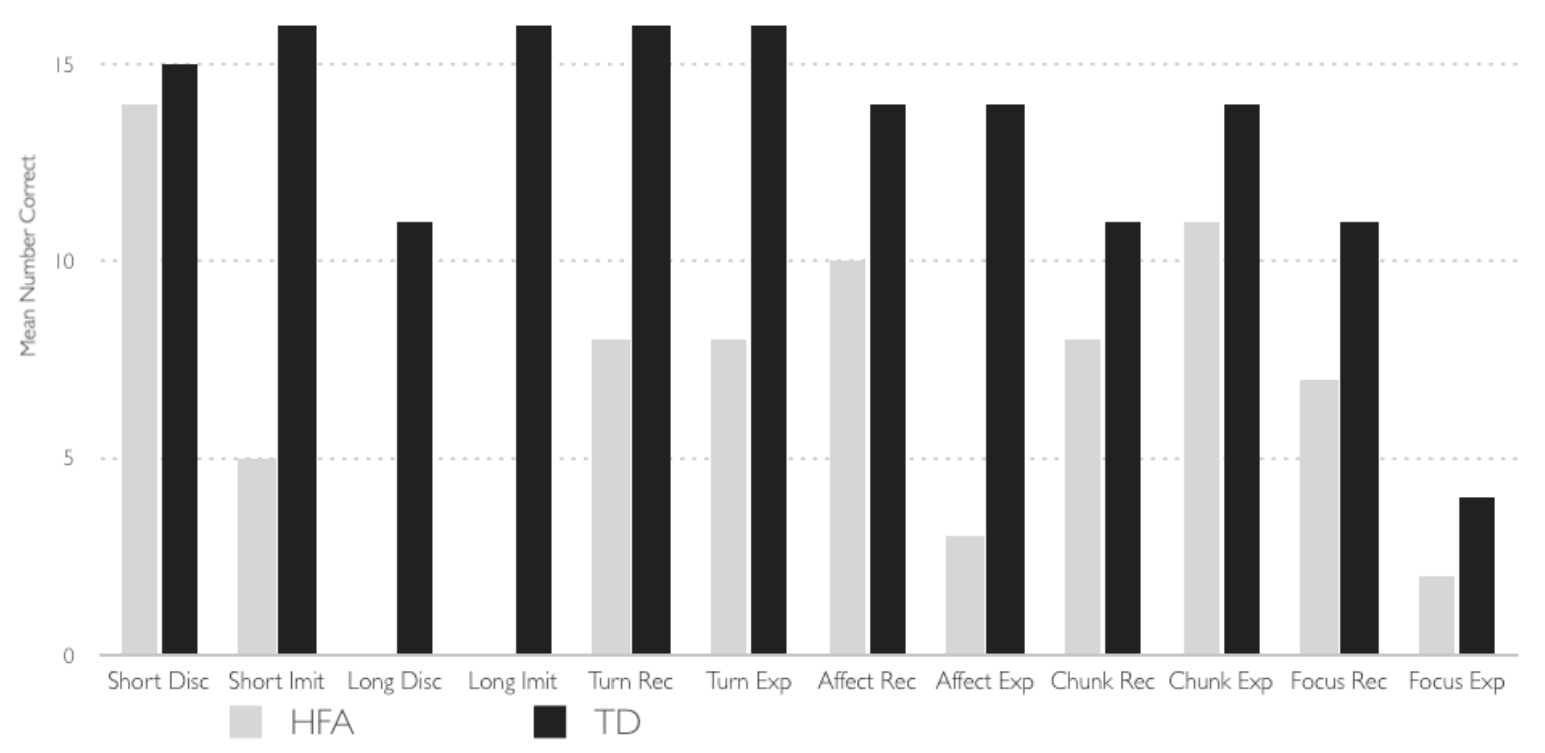

Figure 5. Standardized scores for all the PEPS-C tasks for Case B. (a child with highfunctioning autism, HFA) and a typically developing peer (TD, a child with the same chronological age and nonverbal intelligence). 